NBER WORKING PAPER SERIES

\title{
EARLY RETIREMENT AND PUBLIC DISABILITY INSURANCE APPLICATIONS: EXPLORING THE IMPACT OF DEPRESSION
}

\author{
Rena M. Conti \\ Ernst R. Berndt \\ Richard G. Frank \\ Working Paper 12237 \\ http://www.nber.org/papers/w12237
NATIONAL BUREAU OF ECONOMIC RESEARCH
1050 Massachusetts Avenue
Cambridge, MA 02138 \\ May 2006
}

Corresponding author: Rena Conti, Department of Health Care Policy, Harvard Medical School, 180 Longwood Avenue, Boston, MA 02115. Tel: 617-645-6375, email: rconti@fas.harvard.edu. The authors gratefully acknowledge research support from the Lasker Family Charitable Trust, the National Institutes of Aging and the National Institute of Mental Health (Conti, Frank). The authors are also grateful to David Cutler, Tom McGuire, Joseph Newhouse, health policy research seminar participants at Harvard University and members of the NBER Disability Group for helpful comments and suggestions. The views expressed herein are those of the author(s) and do not necessarily reflect the views of the National Bureau of Economic Research.

(C)2006 by Rena M. Conti, Ernst R. Berndt and Richard G. Frank. All rights reserved. Short sections of text, not to exceed two paragraphs, may be quoted without explicit permission provided that full credit, including (C) notice, is given to the source. 
Early Retirement and Public Disability Insurance Applications: Exploring the Impact of

Depression

Rena M. Conti, Ernst R. Berndt and Richard G. Frank

NBER Working Paper No. 12237

May 2006

JEL No. I12, J21

\author{
Rena M. Conti \\ Department of Health Care Policy \\ Harvard Medical School \\ 180 Longwood Avenue \\ Boston, MA 02115 \\ rconti@fas.harvard.edu \\ Ernst R. Berndt \\ Sloan School of Management \\ MIT, E52-452 \\ 50 Memorial Drive \\ Cambridge, MA 02142 \\ and NBER \\ eberndt@mit.edu \\ Richard Frank \\ Department of Health Care Policy \\ Harvard Medical School \\ 180 Longwood Avenue \\ Boston, MA 02115 \\ and NBER \\ frank@hcp.med.harvard.edu
}

ABSTRACT

This paper investigates the impact of depression on labor force participation among older workers. Empirically, we use two analytic strategies and rely on a sample drawn from the Health and Retirement Survey. Depression directly and indirectly increases individuals' probability of retiring early and applying for DI benefits, after accounting for other predictors of labor force exit. Accounting for the independent effects of depression, disability associated with physical illness may be smaller than the official statistics suggest. There may be great economic gains in increasing depression treatment awareness and access to treatment for individuals, employers and society. 
Early Retirement and Public Disability Insurance Applications:

Exploring the Impact of Depression

\author{
Rena M. Conti ${ }^{1}$ \\ Harvard University \\ Ernst R. Berndt, Ph.D. \\ Massachusetts Institute of Technology and NBER \\ Richard G. Frank, Ph.D. \\ Harvard Medical School and NBER
}

\begin{abstract}
This paper investigates the impact of depression on labor force participation among older workers. Empirically, we use two analytic strategies and rely on a sample drawn from the Health and Retirement Survey. Depression directly and indirectly increases individuals' probability of retiring early and applying for DI benefits, after accounting for other predictors of labor force exit. Accounting for the independent effects of depression, disability associated with physical illness may be smaller than the official statistics suggest. There may be great economic gains in increasing depression treatment awareness and access to treatment for individuals, employers and society.
\end{abstract}

JEL Classification: I10 Health

Key Words: Mental Health, Disability, Retirement

Later middle age is a time of economic stability for most people. This period also begins the transition to reduced health and less active work. The impact of health events in later middle age on employment choices and other indicators of economic wellbeing has been the focus of a

\footnotetext{
${ }^{1}$ Corresponding author: Rena Conti, Department of Health Care Policy, Harvard Medical School, 180 Longwood Avenue, Boston, MA 02115. Tel: 617-645-6375, email: rconti@fas.harvard.edu. The authors gratefully acknowledge research support from the Lasker Family Charitable Trust, the National Institutes of Aging and the National Institute of Mental Health (Conti, Frank). The authors are also grateful to David Cutler, Tom McGuire, Joseph Newhouse, health policy research seminar participants at Harvard University and members of the NBER Disability Group for helpful comments and suggestions.
} 
number of recent economic studies. ${ }^{2,3,4,5,6,7}$ This work has contributed to explaining declines in disability associated with later middle age. ${ }^{8}$

The impact of mental health on activities of people in later middle age has been less extensively studied. Evidence suggests that mental disorders negatively affect labor market activity in both men and women. ${ }^{2}$ Mental health may also affect an individual's ability to respond to adverse health events. Recent reports from the Social Security Disability Insurance (DI) and the Supplemental Security Insurance (SSI) programs highlight the disruption of mental disorders to labor market activities. Since the early 1990s, mental illnesses are the fastest growing cause of new claims for income support from the DI and the SSI programs.9 These trends appear to be concentrated among middle aged pre-retirement adults, ages 45-64.

2 Dwyer DS and Mitchell OS, 1999. Health problems as determinants of retirement: Are self-rated measures endogenous? Journal of Health Economics 182 (1999), pp. 173-193.

3 Ettner SL, Frank R, Kessler R, 1997. The impact of psychiatric disorders on labor market outcomes. Industrial and Labor Relations Review 51, pp. 64-81.

4 Ettner SL, 2000. The relationship between labor market outcomes and physical and mental health Exogenous human capital or endogenous health production? Research in Human Capital and Development, Volume 13, Pages 1-31.

5 Panzarino PJ Jr, 1998. The costs of depression: direct and indirect; treatment versus nontreatment. J Clin Psychiatry 59 Suppl 20:11-4.

6 Lerner D, Adler DA, Chang H, et al, 2004. The Clinical and Occupational Correlates of Work Productivity Loss Among Employed Patients with Depression. Journal of Occupational and Environmental Medicine, 46:6 (supplement), (June), pp, 545-555.

7 Lerner D, Berndt ER, Adler DA, 2004. Unemployment, Job Retention and Productivity Loss Among Employees with Depression. Psychiatric Services, forthcoming.

8 Most recent work has focused on declining disabilities and improved health among Americans 60 years and older (Cutler, 2001; Manton, Gu, 2001). A handful of studies have documented declining disability among Americans 50 years and older (Freedman, Martin Schoeni, 2002; Freedman, Martin, 1998; Freedman, Martin, 1999). For raw trends see National Center for Health Statistics, 2003.

9 Social Security Administration, 2004. Annual Statistical Supplement 1990-2004. Available at www.ssa.gov. Last accessed January 25, 2005. 
In this paper we attempt to develop a better understanding of the potential effects of one major mental health condition, depression, on work related activities among people in later middle age. We hypothesize that depression may negatively impact work participation directly by reducing affected individuals' ability to work and interest in employment. Depression may also indirectly affect work through it's interaction with physical illnesses and other life events. The analyses focus on three sets of outcomes: employment status, early retirement, and application for DI/SSI benefits. To examine the direct impacts of depression on work related outcomes we focus on individuals who experience an incident case of depression and compare these people to similar individuals who did not experience a new episode of depression. To estimate the indirect effects of depression we compare the work activity responses to incident health events (health shocks) and other life events (widowhood) for people likely to have depression and a similar group of people without significant symptoms of depression.

The paper is organized as follows. Section I of this paper presents a brief review of the relevant clinical, epidemiological and economic literature. Section II presents our general conceptual approach to studying these issues and reviews the empirical strategies we employ to estimate the direct and indirect effects. Section III describes the data employed in the analyses. Section IV presents results of simple and more complex empirical analyses and several robustness checks. Section V discusses study findings and implications for individuals and public policy.

\section{Background}

Depression Impairment, Prevalence and Factors Associated with Onset in Middle Age

Depression is characterized by melancholy, diminished interest or pleasure in most or all activities, sleep disorders, and feelings of worthlessness. Depression episodes may come and go, 
last from several weeks to several months and are followed by periods of relatively normal mood and behavior. ${ }^{10}$ There have been substantial advances in the treatment of depression in the past fifteen years. Despite this, depression remains under recognized and under-treated in the adult US population. ${ }^{11,12}$

The National Comorbidity Survey Replication (NCS-R) study finds that $6.6 \%$ of working aged adults experienced an episode of depression in a given year. ${ }^{13}$ Individuals aged 18-59 have a higher risk of lifetime major depressive disorder compared with individuals aged 60 and older. Women are also at higher risk for developing major depressive disorder compared with men. Episodes of depression are associated with significant functional impairment. 14 Major depression accounts for approximately fifty percent of all current DI/SSI claims. ${ }^{15}$

The indirect impact of depression on individuals' lives has been studies in recent clinical and epidemiological research. ${ }^{16}$ Depression has been linked to a number of physical illnesses

10 Spitzer RL, Kroenke K, Linzer M, Hahn SR et al, 1995. Health-related quality of life in primary care patients with mental disorders: results from the PRIME-MD 1000 study. JAMA, 274(19): 1511-1517.

11 U.S. Department of Health and Human Services, 1999. Mental Health: A Report of the Surgeon General-Executive Summary. Rockville, MD: U.S. Department of Health and Human Services, Substance Abuse and Mental Health Services Administration, Center for Mental Health Services, National Institutes of Health, National Institute of Mental Health.

12 McGlynn EA, Asch SM, Adams J, Keesey J, Hicks J, DeCristofaro A, Kerr EA, 2003. The Quality of Health Care Delivered to Adults in the United States. New England Journal of Medicine, Vol. 348, No. 26, pp. 2635-2645

13 Kessler RC, Berglund P, Demler O, Jin R, 2003. The epidemiology of major depressive disorder: results from the National Comorbidity Survey Replication (NCS-R). JAMA 289(23): 3095-3105.

14 Ormel J, VonKorff M, Ustun TB, Pini S, Korten A, Oldehinkel T, 1994. Common mental disorders and disability across cultures: results from the WHO collaborative study on psychological problems in general health care. JAMA 272(22): 1741-1748.

15 Personal communication with SSA research statistician, April 2002. Updated September 2005.

16 Kessler RC, Ormel J, Demler O, Stange PE, 2003. Comorbid mental disorders account for the role impairment of commonly occurring chronic physical disorders: results from the National Comorbidity Survey. J Occup Environ Med 45(12): 1257-66. 
such as heart attacks and heart disease, strokes, diabetes, and cancer. 17, 18, 19,20,21,22, 23,24 ,

$25^{\prime} 26^{\prime} 27 \cdot 28$ The directionality of these relationships is unclear at this time: some studies suggest depression is an important antecedent risk factor for incident physical illness, while others suggest the opposite causal relationship. ${ }^{29,30,31,32,33,34}$ Regardless of the causal

17 Bruce ML and Hoff RA, 1994. Social and physical health risk factors for first onset major depressive episode disorder in a community sample. Social Psychiatry and Psychiatric Epidemiology 29(4); 165171.

18 Carson AJ, MacHale S, Allen K, Lawrie SM, Dennis M, House A, Sharpe M, 2000. Depression after stroke and lesion location: a systematic review. Lancet Jul 8;356(9224):122-6.

19 Gainotti G, Azzoni A, Marra C, 1999. Frequency, phenomenology and anatomical-clinical correlates of major post-stroke depression. Br J Psychiatry Aug;175:163-7.

20 Surtees PG, Wainwright NW, Khaw KT, Day NE, 2003. Functional health status, chronic physical conditions and disorders of mood. Br J Psychiatry Oct;183:299-303.

21 Whyte EM, Mulsant BH, 2002. Post stroke depression: epidemiology, pathophysiology, and biological treatment. Biol Psychiatry Aug 1;52(3):253-64.

22 Robinson RG, Morris PL, Fedoroff JP, 1990. Depression and cerebrovascular disease. J Clin Psychiatry Jul;51 Suppl:26-31; discussion 32-3.

23 Bottomley A, 1998. Depression in cancer patients: a literature review. Eur J Cancer Care Sep;7(3):181-91.

24 Spiegel D, 1996. Cancer and depression. Br J Psychiatry Suppl Jun;(30):109-16.

25 Zellweger MJ, Osterwalder RH, Langewitz W, Pfisterer ME, 2004. Coronary artery disease and depression. Eur Heart J Jan;25(1):3-9.

26 Rudisch B and Nemeroff CB, 2003. Epidemiology of comorbid coronary artery disease and depression. Biol Psychiatry Aug 1;54(3):227-40.

27 O'Connor CM, Gurbel PA, Serebruany VL, 2000. Depression and ischemic heart disease. Am Heart J. Oct;140(4 Suppl):63-9.

28 Musselman DL, Betan E, Larsen H, Phillips LS, 2003. Relationship of depression to diabetes types 1 and 2: epidemiology, biology, and treatment. Biol Psychiatry Aug 1;54(3):317-29.

29 Krishnan KR, 2000. Depression as a contributing factor in cerebrovascular disease. Am Heart J Oct;140(4 Suppl):70-6.

30 Larson SL, Owens PL, Ford D, Eaton W, 2001. Depressive disorder, dysthymia, and risk of stroke: thirteen-year follow-up from the Baltimore epidemiologic catchment area study. Stroke Sep;32(9):197983. 
direction, comorbid depression appears to worsen the prognosis, prolong recovery and may increase the risk of mortality associated with the physical illness. $35,36,37,38,39,40,41,42,43,44$

31 Stewart RA, North FM, West TM, Sharples KJ, Simes RJ, Colquhoun DM, White HD, Tonkin AM, 2003. Long-Term Intervention With Pravastatin in Ischaemic Disease (LIPID) Study Investigators. Depression and cardiovascular morbidity and mortality: cause or consequence? Eur Heart J Nov;24(22):2027-37.

32 Dalton SO, Boesen EH, Ross L, Schapiro IR, Johansen C, 2002. Mind and cancer. do psychological factors cause cancer? Eur J Cancer Jul;38(10):1313-23.

$33 \mathrm{Wulsin}$ LR, 2004. Is depression a major risk factor for coronary disease? A systematic review of the epidemiologic evidence. Harv Rev Psychiatry Mar-Apr;12(2):79-93.

34 MacMahon KM and Lip GY, 2002. Psychological factors in heart failure: a review of the literature. Arch Intern Med Mar 11;162(5):509-16.

35 Black SA, Markides KS, Ray LA, 2003. Depression predicts increased incidence of adverse health outcomes in older Mexican Americans with type 2 diabetes. Diabetes Care Oct;26(10):2822-8.

36 Fultz NH, Ofstedal MB, Herzog AR, Wallace RB, 2003. Additive and interactive effects of comorbid physical and mental conditions on functional health. J Aging Health Aug;15(3):465-81.

37 House A, Knapp P, Bamford J, Vail A, 2001. Mortality at 12 and 24 months after stroke may be associated with depressive symptoms at 1 month. Stroke Mar;32(3):696-701.

38 Jiang W, Babyak MA, Rozanski A, Sherwood A, O'Connor CM, Waugh RA, Coleman RE, Hanson MW, Morris JJ, Blumenthal JA, 2003. Depression and increased myocardial ischemic activity in patients with ischemic heart disease. Am Heart J Jul;146(1):55-61.

39 Kotila M, Numminen H, Waltimo O, Kaste M, 1999. Post-stroke depression and functional recovery in a population-based stroke register. The Finnstroke study. Eur J Neurol May;6(3):309-12.

40 Ostir GV, Goodwin JS, Markides KS, Ottenbacher KJ, Balfour J, Guralnik JM, 2002. Differential effects of premorbid physical and emotional health on recovery from acute events. J Am Geriatr Soc Apr;50(4):713-8.

41 Ramasubbu R and Patten SB, 2003. Effect of depression on stroke morbidity and mortality. Can J Psychiatry May;48(4):250-7.

42 Williams LS, Ghose SS, Swindle RW, 2004. Depression and other mental health diagnoses increase mortality risk after ischemic stroke. Am J Psychiatry Jun;161(6):1090-5.

43 Carney RM and Freedland KE, 2003. Depression, mortality, and physical morbidity in patients with coronary heart disease. Biol Psychiatry Aug 1;54(3):241-7.

44 Rozanski A, Blumenthal JA, Kaplan J, 1999. Impact of psychological factors on the pathogenesis of cardiovascular disease and implications for therapy. Circulation Apr 27;99(16):2192-217. 
Major life changes, such as widowhood, have been linked to the onset of depression in middle aged adults. ${ }^{45,46}$ In particular, there appears to be important gender differences regarding the negative consequences of depression associated with deteriorating physical health and other factors. ${ }^{14,47}$ The quality of the epidemiological evidence associating depression in middle aged adults with other social factors varies substantially. In the few studies that appear to use well-defined and reliable measurements of depressive symptoms and social characteristics, small sample sizes and/or highly specific study populations tend to be employed, limiting the statistical power and generalizability of the findings. With respect to life changes, it is unclear from the epidemiological literature whether these factors affect the severity of illness or are precipitating factors in incident depression episodes.

\section{Previous Economic Literature}

The existing literature focuses exclusively on direct impacts of illness on employment, earnings and hours of work. A number of studies have documented the direct effects of poor health on contemporaneous labor force participation, DI/SSI applications and benefit receipt, and early retirement. $48,49,50,51,52,53,54,55,56,57$ The majority find that poor health is negatively

45 Perreira KM and Sloan FA, 2002. Excess alcohol consumption and health outcomes: a 6 year followup of men over age 50 from the health and retirement study. Addiction 97; 301-310.

46 Bruce ML, 2002. Psychosocial risk factors for depressive disorders in late life. Biological Psychiatry $52 ; 175-184$.

47 Bruce ML and Kim KM, 1992. Differences in the effects of divorce on major depression in men and women. American Journal of Psychiatry 149(7); 914-7.

48 Bazzoli GJ, 1985. The Early Retirement Decision: New Empirical Evidence the Influence of Health. The Journal of Human Resources, Vol. 20, No. 2. (Spring), pp. 214-234.

49 Bartel A and Taubman P, 1979. Health and labor market success: The role of various diseases. Review of Economics and Statistics 61 (1979), pp. 1-8. 
associated with labor force participation and positively correlated with DI/SSI applications.

More recent work has focused on declining health's negative impact on employment. 58, 59

Only two studies we identified explicitly decompose health measures into physical and mental

illness. ${ }^{60,47}$ When such distinctions are made, mental illnesses appear to significantly increase

the likelihood of labor force exit and disability program application and receipt.

Most of the early literature treated health and health deterioration as exogenous to

employment status. In contrast, a growing body of research recognizes that health and labor

50 Berkovec J and Stern S, 1991. Job Exit Behavior of Older Men. Econometrica, Vol. 59, No. 1. (Jan.), pp. 189-210.

51 Burtless G, 1987. Occupational effects on the health and work capacity of older men. In G. Burtless (Ed.), Work, health and income among the elderly (pp. 103-150). Washington, DC: Brookings Institution.

52 Chirikos TN and Nestel G, 1985. Further evidence on the economic effects of poor health. Review of Economics and Statistics 67, pp. 61-69.

53 Quinn JF, 1977. Microeconomic Determinants of Early Retirement: A Cross-Sectional View of White Married Men. The Journal of Human Resources, Vol. 12, No. 3. (Summer), pp. 329-346.

54 Fenn PT and Vlachonikolis IG, 1986. Male Labour Force Participation Following Illness or Injury. Economica, New Series, Vol. 53, No. 211. (Aug.), pp. 379-391.

55 Breslaw JA and Stelcner M, 1987. The Effect of Health on the Labor Force Behavior of Elderly Men in Canada. The Journal of Human Resources, Vol. 22, No. 4. (Autumn), pp. 490-517.

56 Chirikos TN, 1993. The relationship between health and labor market status. Annual Review of Public Health 14, pp. 293-312.

57 Costa D, 1996. Health and labor force participation of older men, 1900-1991. Journal of Economics History 56, pp. 62-89.

58 Bound J, Schoenbaum M, Stinebrickner TR and Waidmann T, 1999. The dynamic effects of health on the labor force transitions of older workers. Labour Economics, Volume 6, Issue 2, (June), Pages 179202.

59 Pelkowski JM and Berger MC, 2004. The impact of health on employment, wages, and hours worked over the life cycle. The Quarterly Review of Economics and Finance, Volume 44, Issue 1, February, pp. 102-121.

60 Berkowitz M and Johnson WG, 1974. Health and Labor Force Participation. The Journal of Human Resources, Vol. 9, No. 1. (Winter), pp. 117-128. 
supply are jointly determined. ${ }^{1}$ While the health production framework is well developed, empirical estimation strategies are more varied. When the possible endogeneity of mental health and labor supply is taken into account, there still appears to be significant decrements in employment, earnings and hours of work for both men and women. ${ }^{2,3,4,5,6}$

Finally, consistent with a handful of recent clinical findings, several papers have viewed retirement as a process rather than a single event and often that of last resort ${ }^{61,62}$ Few papers have estimated the direct effect of health on labor force transitions other than the events of retirement, DI application and DI receipt. 63 Two recent studies have investigated the dynamic effects of declining physical health on labor force participation and DI application and receipt in older workers. ${ }^{55,64}$ In the first study the authors report that declines in physical health are strongly associated with labor force exit, job change, and DI applications. In the second, the authors find that negative physical health shocks appear to increase out of pocket health care expenses, decrease the extensive margins of labor supply (whether to work or not), increase health insurance access primarily through government programs, and decrease household income.

\section{Conceptual Framework and Analytical Plan}

61 Honig M and Hanoch G, 1985. Partial Retirement as a Separate Mode of Retirement Behavior . Journal of Human Resources vol 20 (1), pp. 21-46 .

62 Ruhm C J, 1990. Bridge Jobs and Partial Retirement. Journal of Labor Economics, vol. 8 (4), pp. $482-501$.

63 Blau DM, 1998. Labor Force Dynamics of Older Married Couples. Journal of Labor Economics vol. 16 (3), pp. 595-629.

64 Smith JM, 2005. Transitions in Health and Labor Supply. Working Paper. 
Taking the human capital model as a point of departure, we hypothesize that incident depression directly decreases labor supply. Based on clinical and epidemiological research, we also hypothesize that depression creates a new vulnerability to other shocks that may also negatively affect labor supply. These proposed pathways are summarized in Figure A. In terms of life events, we focus on widowhood, since it appears to be independently and robustly associated with the onset of depression in middle age, is easily and reliably measured in survey data, and is plausibly associated with employment opportunities and outcomes.

\section{Labor Market Participation/ Disability Program Application}

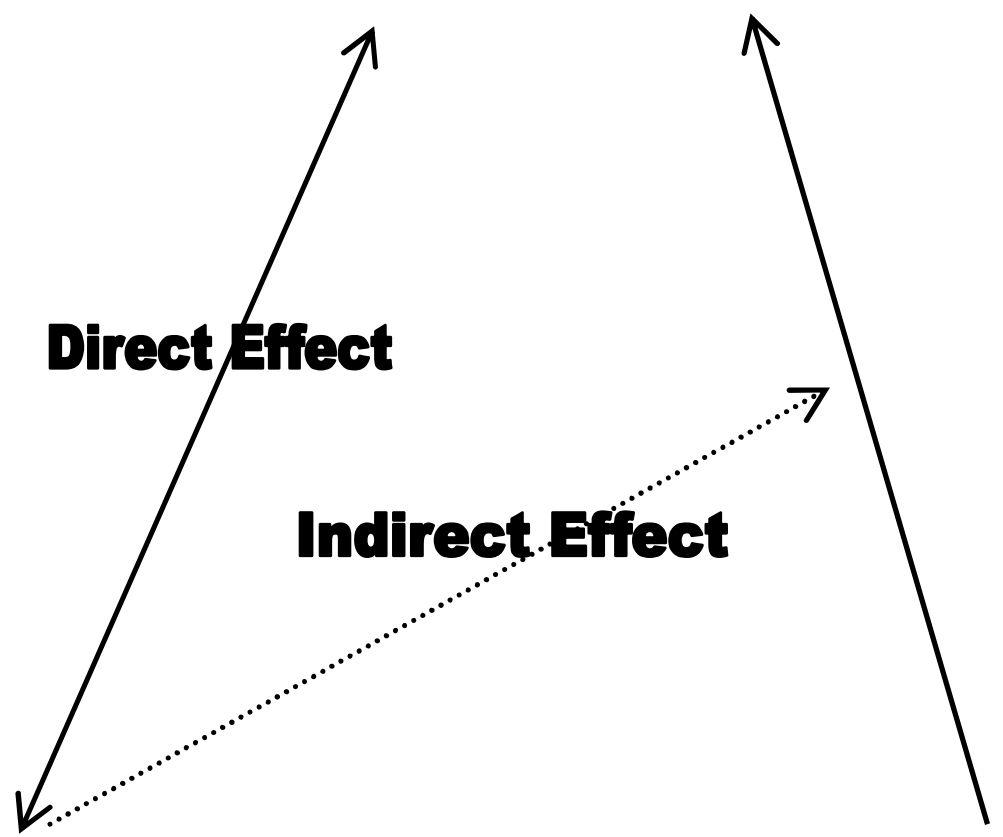

\section{Depression}

Physical Illness, Other Life Events

Figure A. The Direct and Indirect Effects of Depression on Labor Market Participation and Disability Program Application

We adopt two empirical approaches to estimate these effects and to address the potential endogeneity of depression in labor supply (depicted above as a reverse arrow leading from labor market outcomes to depression). In the first approach, we identify a subset of employed people likely to be depressed at baseline and compare their employment outcomes in subsequent survey 
waves with those of individuals who are not depressed. We interact baseline depression with incident physical illness (subsequent to the baseline) and widowhood to identify the indirect effects depression may have on the employment outcomes associated with these life events. The incremental effect of depression on labor market activity either alone or in combination with another life events compared to that of individuals with no existing depression are estimated using difference in differences. For these analyses we control for baseline characteristics of individuals and obtain standard errors that account for the panel structure of the data. ${ }^{65}$

The second method identifies a subset of individuals with no history of psychiatric conditions and no significant symptoms of depression at baseline. Individuals are excluded from the study cohort if they have a physical illness or have lost a spouse at baseline. We estimate the direct incremental effect of incident depression on labor supply and disability program participation compared to individuals with no incident depressive episode using generalized estimating equations. We also estimate the incremental indirect effect of incident depression associated with incident physical illness and widowhood on employment outcomes compared to individuals with no incident life shock.

We estimate both models using maximum likelihood. The generalized estimating equations (GEE) model is used to account for the panel structure of the data with non-Gaussian outcomes. ${ }^{66}$ To aid in the interpretation of results, we calculate predicted probabilities for each

65 For all analyses reported in the paper we assume errors are clustered on an individual. We repeated analyses specifying AR1, AR2, AR3 and exchangeable errors terms within individuals. The results of the analyses do not change significantly.

66 We estimated both sets of analyses using conditional logits, and random effect probits in addition to using GEE. We report in this paper results of the GEE analyses. The results do not significantly differ between estimating procedures. The advantage of GEE over other methodologies is its flexibility in discrete modeling of the error term and its small sample properties. However, GEE has been shown to be biased in estimating causal effects in unbalanced panels. For this reason we chose to restrict our sample to a continuously enrolled population. 
of the outcomes under differing health and mental health states and obtain bootstrapped standard errors. We also perform several sensitivity analyses to assess the robustness of our findings.

We limit our analyses to individuals who are working at baseline to attenuate the possibility that loss of employment may cause an individual to experience depression at baseline or in subsequent periods. We also include regional indicator variables (northeast, south, west and midwest) to account for differing economic conditions across the nation. We include an interaction term between region and time dummies to control for differential regional employment and disability application trends. Finally, we include a number of demographic variables in our models that may impact labor market choices, including a respondent's race, educational attainment and household wealth (total assets and non-housing total assets).

Given differing labor market participation incentives and opportunities, as well as depression incidence for women and men, we stratify all analyses by gender. We also exclude individuals aged 65 years or older in the baseline period in all the analyses. We control for marital status in the baseline period and subsequent changes in marital status excluding widowhood in all empirical analyses. Finally, where possible we check dates of outcomes such as disability application, loss of a job and retirement against interview dates to help control for the possibility of retirement, disability application and loss of a job preceding the depression episode. We excluded all individuals from our analyses who experience a job loss previous to reporting a health or life shock. All outcomes are assessed at year $t+1$ when depression occurs in year t. ${ }^{67}$

III. Data

67 Responses in the last survey year are the exception. Here we take advantage of the timing of health and employment survey modules. The HRS fields three separate surveys in a given two year survey wave. In the final wave, we use the health responses from the first survey and employment responses from the last survey. The average timing between surveys is 9 months. 
The analysis is conducting using data from the Health and Retirement Survey (HRS). 68 The survey includes a representative sample of non-institutionalized men and women born between 1931 and 1941 inclusive, and their spouses or partners. The HRS oversamples blacks, Hispanics and residents of the state of Florida, and provides population weights for analyses. ${ }^{69}$ The first wave was conducted in the Spring of 1992 and the Winter of 1993 on approximately 7,600 households (12,654 individuals). The first follow up of HRS respondents was fielded approximately two years after the baseline; later waves of the survey have been fielded through 2002. ${ }^{70}$

The HRS contains extensive measures of income, assets, health insurance coverage, demographic characteristics and family structure. Among these variables we use measures of employment including full time and part time work status, early (pre age 65) retirement and application for DI/SSI benefits (DI, SSI and DI/SSI). Since approximately $75 \%$ of individuals who apply for DI benefits initially are rejected, and approximately $55 \%$ of these reapply or appeal this initial eligibility determination, often we do not observe the resolution of the application process. ${ }^{7}$ Hence, we only include DI/SSI benefit application and appeals in our analyses. Previous studies have suggested that women may be less likely to report being retired when they have exited the labor market than men. Results of a preliminary analysis of the dataset are consistent with this observation: women are less likely to report being "retired" and more likely to report being "not in the labor force" conditional on previous employment in comparison to men overall. Therefore, we consider individuals in the main analyses to be retired

68 University of Michigan, 1999. Health and Retirement Study: Survey Design. Available at www.umich.edu/ rswww/studydet/desgn.html. Last accessed September 15, 2004.

69 Population weights are used for all analyses.

70 Juster FT and Suzman R, 1995. An overview of the health and retirement study. Journal of human resources 30: S7-S27. 
if they report being "retired" or "left the labor force" in response to a survey question regarding self reported labor force status conditional on previous employment.

The HRS contains an extensive range of health measures, including the prevalence of 39 specific health conditions and a depression index based on the CES-D. We employ measures of health conditions linked to depression in the clinical literature, specifically cardiovascular problems (including heart attacks and cardiovascular disease and excluding high blood pressure), stroke, (any) cancer and diabetes.

Depression diagnosis is not part of the health conditions specifically identified. 71 Therefore, our primary measure of depression is derived from the CES-D. The CES-D is a self report survey instrument designed to measure the current prevalence of depressive symptoms in the general population. ${ }^{72}$ A shortened version of the full CES-D questionnaire is administered in the HRS, consisting of 8 questions, each scored on a scale of 0-1. A response of zero indicates that the respondent did not experience the symptom in the past year; a score of one indicates the reverse. One major advantage of the CES-D for use in our study is that none of the measures is related to employment or work performance, thereby providing a measure of depression symptomology independent of work outcomes.

Identification of individuals likely suffering from a depressive episode is predicated on the reliability and validity of CES-D cutoff scores. In order to best identify individuals using this score we relied on an extensive literature on the usefulness of the CES-D in identifying episodes of depression. No equivalent validity and reliability studies for shortened CES-D instruments have been performed in older populations to date. Short forms of the CES-D have been

71 Steffick DE, 2000. Documentation of affective functioning measures in the health and retirement study. Ann Arbor, MI: Survey Research Center, University of Michigan. Available at www.umich.edu.

72 Radloff LS, 1977. The CES-D scale: a self report depression scale for research in the general population. Applied psychological measurement 1(3); 385-401. 
validated for general adult use and shown to be reliable and internally consistent in detecting probable depression. ${ }^{73,74}$ Several methods have been advanced to convert a cutoff score consistent with probable depression in the full survey (typically 16 out of a total possible score of 60) to the shortened version, each yielding similar results (a score of 2-3 out of a possible total score of 8 on the HRS version of the CES-D). ${ }^{75}$ One recent paper has investigated the validity of the full CES-D for recognizing depression in older community dwelling populations, aged 55 and older. 76 They report that the optimal cutoff score for identifying major depression in an older adult population using the full CES-D to be $20-21$ out of a possible total score of 60 . A score of 20-21 on the full CES- D survey is equivalent to a cutoff score of 4 in the shortened version using the proportionality method advanced by Kohout et al (1993). We implement this cutoff in our sample; the primary measure of depression that we apply to our sample is an aggregate score of 4 or higher on the shortened CES-D in a given year.

\section{Study Cohort Definitions and Exclusions}

For all analyses, we employ survey responses of individuals continuously enrolled between 1994 and 2000 (waves 2-5). We concentrate on this time period due to concerns regarding changes in the inclusion of specific CES-D questions in the depression screener and

73 Kohout FJ, Berkman LF, Evans DA, Cornoni-Huntley J, 1993. Two shorter forms of the CES-D depression symptoms index. Journal of Aging and Health May; 5(2): 179-93.

74 Andresen EM, Mamgren JA, Carter WB, Patrick DL, 1994. Screening for depression in well older adults: evaluation of a short form of the CES-D. American Journal of Preventive Medicine 10(2); 77-84.

75 Several researchers have suggested that findings from younger patient groups regarding the validity and reliably of implementing corresponding cutoffs in the full CES-D for detecting major depression may not apply to older persons. Specifically, older adults tend to underreport depressive symptoms. Comorbid physical illnesses may also confound questions regarding somatic symptoms of depression. 76 Lyness JM, Noel TK, Cox C, King DA, Conwell Y, Caine ED, 1997. Screening for depression in elderly primary care patients. A comparison of the Center for Epidemiologic Studies-Depression Scale and the Geriatric Depression Scale. Arch Intern Med Feb 24;157(4):449-54. 
changes in the specific wording of allowable CES-D responses between years 1992 and $1994 .{ }^{77}$ Responses from the 1994 survey are considered to be the "baseline" measures and as such define the before period of our study. Individuals are included in the study sample if they report that they worked during 1994, defined as working part or full time, not retired and not unemployed. In the first set of analyses, we exclude all individuals who reported having diabetes, heart disease, back pain, cancer or had a stroke in 1994 or earlier. We also exclude all individuals who report being a widow in 1994. In the second set of analyses, individuals who report a history of psychiatric problems or experience depressive symptomology consistent with depression in 1994 are excluded from the sample. We also excluded all individuals who reported having diabetes, heart disease, cancer or had a stroke in 1994 or earlier. In the second analyses we also exclude individuals who report being a widow in 1994.

IV. Results

\section{First Analytical Strategy Results}

We identified 2,457 men and 2,986 women respondents to the HRS that met our study criterion (Table 1a). Men were on average approximately two years older than women (54.6 vs. 52.3 years of age). Approximately $6 \%$ of men and $12 \%$ of women were depressed at baseline based on our CES-D definition. Depressed men and women were more likely to experience a subsequent physical health shock in years 1996-2000 (30.3\% among men and 18\% among women) than individuals who were not depressed at baseline (20.3\% among men and $13.5 \%$ among women). However, the incidence of widowhood in years 1994-2000 did not appear to be different for individuals depressed and not depressed at baseline (approximately $2.3 \%$ of men and $7.1 \%$ of women in each group).

77 See Jones and Fonda (2004), for a new method to link responses from wave one and wave two in the HRS. 
We compared characteristics of depressed and not depressed individuals at baseline. The results are tabulated in Table 2. Generally, a larger proportion of Hispanic individuals, those having less than a high school education, and poorer individuals (measured by housing and nonhousing assets) comprise the depressed than the non-depressed population at baseline. We controlled for these differing baseline characteristics in all analyses.

First differences (the direct effect of depression) and difference in differences (the indirect effect of depression) estimates are presented in Table 3. Baseline depression alone appears to increase significantly DI/SSI applications and retirement among both men and women. Subsequent physical illnesses are positively associated with increased retirement and DI/SSI applications among men. Subsequent widowhood alone appears to be positively associated with labor force exit for both men and women. The interaction of baseline depression with subsequent physical illness reduces full time work for men, but has no significant impact on women's employment status. Baseline depression and subsequent widowhood appears to also have differential effects by gender; increasing retirement among men, but increasing DI/SSI applications and decreasing part time work and the likelihood of holding a second job among women.

To aid in the interpretation of these findings we used the regression parameter estimates to construct the predicted mean direct effects of depression alone, physical illness alone and widowhood alone, and predicted mean indirect effects of depression interacted with incident physical illness and subsequent widowhood, on DI/SSI applications (Chart 1a and b) and early retirement (Chart $2 \mathrm{a}$ and $\mathrm{b}$ ). All predicted effects are significantly different from zero at the 0.05 level using bootstrapped standard errors depicted as error bars in the figures. Generally, we find baseline depression alone appears to have a greater impact on predicting DI/SSI applications than incident physical illness alone. The interaction of baseline depression and incident physical 
illness increases the probability of applying for DI/SSI benefits (relative to only baseline depression or only subsequent physical illness) slightly for men. For women, the increase is substantial. For both men and women, while incident widowhood alone has only a small impact on the probability of applying for DI/SSI benefits, when interacted with baseline depression, subsequent widowhood has a large impact. Specifically, the interaction of baseline depression and subsequent widowhood increases both men's and women's likelihood of applying for DI/SSI benefits approximately four-fold over widowhood alone.

With respect to early retirement behavior (Chart $2 \mathrm{a}$ and $\mathrm{b}$ ), men appear to be more affected by physical health and widowhood shocks than are women. For men, the effect of physical illness alone on early retirement is larger than baseline depression alone. The interaction of widowhood and baseline depression generates a positive impact on men's early retirement behavior. However, the interaction of baseline depression and subsequent physical illness does not appear to differentially effect retirement. Similarly, the interaction of baseline depression and subsequent physical illness among women has no differential impact from that of subsequent physical illness alone. For women, the combination of baseline depression and subsequent widowhood has large impact on early retirement, but smaller than that for men.

\section{Second Analytical Strategy Results}

A total of 3,277 respondents to the HRS were included in the second set of analyses, 1,345 men and 1,821 women (Table 1b). Cumulatively, 139 men (10.1\%) and 218 women (14.5\%) experienced an incident episode of depression based on our CES-D definition, while $2.4 \%$ of men and $6.6 \%$ of women lost a spouse. Among individuals with subsequent episodes of depression, a larger percentage of men and women also developed an incident physical illness 
( $26.1 \%$ and $18.7 \%$ respectively) than those without subsequent depression $(18.3 \%$ among men and $12.7 \%$ among women).

GEE estimates of the direct and indirect effects of incident depression on various labor market outcomes are presented in Table 4. For men, incident depression alone and incident physical illness alone appears to increase DI/SSI applications, and decrease employment overall, by approximately the same amount. The interaction between depression and physical illness increases the likelihood of DI/SSI application substantially. While subsequent widowhood alone has little impact on the employment status and DI/SSI application measures, the interaction of depression and widowhood appears to significantly increase DI/SSI application and early retirement among men. For women, depression alone directly decreases employment overall, and when interacted with subsequent physical illness also directly increases the likelihood of DI/SSI applications; this interaction does not appear to have an effect on other measures of employment status or retirement behavior. While by itself subsequent widowhood has no impact on the various employment status measures, the interaction of incident depression with widowhood appears to increase the likelihood of DI/SSI application substantially, but has no significant effect on other employment and retirement outcomes.

To aid in the interpretation of these coefficients, we compute the mean predicted outcomes of the direct effects of depression, physical illness, and widowhood and their interactions on DI/SSI applications and early retirement. Results are reported in Chart $3 \mathrm{a}$ and $\mathrm{b}$ and Chart $4 \mathrm{a}$ and $\mathrm{b}$. All estimated predicted probabilities are significantly different from zero using bootstrapped standard errors depicted as error bars in the figures.

For men, incident depression alone increases the likelihood of applying for disability benefits by 16 percent. This effect appears to be less than but approximately of the same order of magnitude than incident physical illness (increases DI/SSI applications by 25\%). The 
interaction of incident depression and physical illness appears to have a larger effect on the likelihood of men applying for DI/SSI than each illness alone. Widowhood alone increases a man's likelihood of applying for disability benefits by 18 percentage points, similar in magnitude to incident depression and physical illness alone. Interestingly, the interaction of depression and widowhood increases the relative odds of applying for DI/SSI benefits by approximately twofold, to 32 percent, larger than incident depression and incident widowhood alone. For women, the magnitude of the direct effect of depression on DI/SSI applications is equivalent to men. However, incident physical illness alone and its interaction with depression appear to have a larger effect on DI/SSI applications for women in comparison to men. The indirect effect of depression and widowhood appears to be greater for men than for women (14 percent vs. 12 percent). The direct effect of incident widowhood on DI/SSI application for women is similar to that of men as is the interaction of incident widowhood and depression, raising the likelihood of applying for DI/SSI benefits substantially more than each condition alone.

With respect to early retirement (Chart $4 \mathrm{a}$ and $\mathrm{b}$ ), incident depression appears to have a larger effect on the early retirement for women than physical illness alone, while for men the effects are similar. Women appear to be more likely to retire early due to the effects of incident depression alone than are men. The interaction of incident depression and physical illness increases the likelihood of early retirement more than the direct effects of depression and physical illness alone and are similar for men and women. Finally, while the effect on early retirement of incident widowhood alone is similar for men and women (in both cases being slightly smaller than physical illness alone) for men (but not for women) the interaction between incident depression and widowhood is considerably larger than each direct effect and greater than the indirect effect of depression and physical illness combined. 


\section{Sensitivity Analyses}

To test the robustness of our findings, we performed a series of sensitivity analyses.

First, we experimented with the definition of incident physical illness. In one set of analyses, we restricted our definition of incident physical illness to include only heart disease, the largest group of incident physical illnesses experienced by the study cohorts. Generally, the significance of the results reported above do not change, however, the predicted probabilities of applying for DI/SSI benefits and early retirement are lower than those estimated with all physical illnesses included in the models.

The clinical and epidemiological literature has associated pain in general and in particular back pain with depression among older adults. $78^{\prime} 79^{\prime} 80$ Accounting for this association may be important to labor market outcomes, particularly DI/SSI applications, since musculoskeletal problems alone are currently the second leading cause of DI/SSI applications. 81 Therefore, in another set of analyses we expanded the definition of incident physical illness to include incident back pain, re-estimated the models and computed predicted mean direct and indirect effects of depression. Generally, for both men and women this addition elevated the predicted probability of applying for DI/SSI benefits and for retiring early over the original definition. Interestingly, this addition appears largely to eliminate the differential results discussed above between genders. This appears to be because more men than women report incident back pain problems.

78 Bair MJ, Robinson RL, Katon W, Kroenke K, 2003. Depression and pain comorbidity: a literature review. Arch Intern Med 163(20): 2433-45.

79 Eaton, W and Buka S, 2004. The epidemiology of mental illness. Available at www.jhsph.edu/weaton/pubs. Last accessed September 27, 2004.

80 Larson SL, Clark MR, Eaton WW, 2004. Depressive disorder as a long term antecedent risk factor for incident back pain: a 13 year follow-up study from the Baltimore Epidemiological Catchment Area sample. Psychological medicine 34, 211-219.

81 Autor D and Duggan M, 2003. The rise in disability recipiency and the decline in unemployment. Quarterly Journal of Economics, February, p. 157-206. 
To address the possibility that our definition of early retirement may be subject to measurement error due to differential reporting by gender correlated with depression and physical illness onset, we re-estimated the models using a more exclusive measure of retirement behavior. Specifically, we considered individuals to have exited the labor force if they report being "retired" in response to a survey question regarding self reported labor force status. Generally, for men, the direction and magnitude of the direct and indirect effects of depression using the more exclusive measure of retirement are consistent with our original findings. However, women are more likely to report being "not in the labor force" conditional on previous employment in comparison to men overall. Thus, we expected that use of the alternative outcome measure may be particularly sensitive to women's labor market participation. We find that the results are consistent with this expectation: the direct effects of incident depression, incident physical illness and widowhood alone appear to be approximately half as large with respect to the likelihood of retiring (and remain statistically significant) for women. The indirect effects of depression associated with physical illness and depression associated with widowhood are similarly smaller and remain statistically significant.

The CES-D is an instrument that does not directly provide information on a diagnosis of depression. In particular, it does not contain questions regarding duration and frequency of symptoms that are important diagnostic criteria. Thus, our reliance on the CES-D to determine depression cases may result in misclassification error. In order to assess our identification of cases of depression, we compare case classifications using the CES-D to the one time fielding of a separate depression assessment tool, the Composite International Depression Instrument (CIDI), in the HRS that directly relates to the DSM-III diagnostic criteria. The HRS fielded the so called CIDI short form in the wave 3 (1996) survey only. A cutoff score of 5 out of 7 corresponds to a DSM-III diagnosis of major depression with high sensitivity and specificity. ${ }^{64}$ 
Applying the CIDI criteria to the second study cohort, we identified a lower percentage of men and women (2.4\% and 6.6\% respectively) with depression compared to that classified as depressed when using the CES-D criteria in wave 3 only (7\% and $9.6 \%$ respectively). In order to determine the overlap in depression cases identified by both surveys we ran a probit regression of CESD cases on CIDI cases at the individual level. We found that determination of depression cases using the CES-D criteria identifies as depressed approximately $79 \%$ of individuals meeting depression criteria using the CIDI criteria. This represents a relatively high correlation between the two depression measures. The high concordance in depression identification indicated by comparisons between the CES-D and CIDI and the higher numbers of absolute cases attributed to the CES-D criteria suggest that the CES-D does a good job of predicting major depression, but may over-identify cases when duration in particular is not accounted for in the determination process. Therefore, misclassification of depression using the CES-D criteria alone likely results in a downward bias in the estimation of the direct and indirect effects of depression on labor force participation since some transient symptoms of depression are overweighted in the analyses and results. ${ }^{82}$

In our empirical approaches to identifying the direct and indirect roles of depression in determining labor force participation, we have concentrated on defining depression to be incident (in the second analytical strategy) or pre-existing (in the first analytical strategy) in an attempt to address concerns regarding the endogeneity of employment and health status. Persistence of depressive symptomology and its potential impact on employment is a challenging issue. For the first strategy, we included in the regression specification a dummy variable if depression occurred in a subsequent survey wave. In the second strategy, once an individual has an incident

82 In a separate set of analyses, we applied a more restrictive definition of depression, employing a cutoff score of 5 on the shortened CES-D, to the cohorts and re-estimated the models. For several outcomes we were unable to achieve convergence using maximum likelihood when applying this criteria. For the remaining analyses, the results were consistent with reported predicted probabilities discussed above. 
depressive episode, we examine labor market outcomes in the subsequent survey year. For individuals who have persistent depression (i.e. remain depressed in a subsequent survey wave) we estimate subsequent labor market outcomes for this depression, which may be more properly considered "prevalent". Both approaches represent conservative approaches to parameter estimation.

In an effort to evaluate the importance of persistent depressive symptoms in determining employment outcomes, we performed a small cross sectional analysis using wave 5 (2000) data. Specifically, we created a cumulative measure of depression across the previous survey years (applying the exclusion criteria used to determine the cohorts in the first and second analyses separately). We then estimated the likelihood of DI/SSI application, retirement and employment status outcomes in the cross-section predicted by the number of depressive episodes experienced by an individual in the current and previous waves. In general, the persistence of depressive symptoms is estimated to increase the relative odds of applying for DI/SSI benefits and early retirement for both men and women. The effect of persistent depression is estimated to be monotonically increasing for men in DI/SSI applications and in retirement for both men and women. Notably, the persistence of depressive symptoms appears to be greater in women than in men.

Finally, to assess the robustness of these estimates we project disability application rates and employment trends for men and women into an out-of-sample survey wave (wave 6, year 2002) using parameter estimates from our model. We then compared these results against actual employment and disability application rates contained in the recently released 2002 HRS data using computed measures of sensitivity and specificity. ${ }^{83}$ To take into account the changing

83 Sensitivity is defined as the proportion of individuals predicted to have a positive outcome (i.e. apply for DI/SSI benefits and retire) who actually have these outcomes in 2002; specificity is the proportion of 
population surveyed in wave 6, we limited our predictions to individuals working in 1994, with no physical illness, depression in 1994 and non-widows who are continuously enrolled in the HRS survey between 1994 and 2002. This yielded a sample of 948 men and 1,460 women. The projections for the 2002 cohort differ by outcome. For DI/SSI application, the predictive power of the model is highly specific, predicting accurately approximately $96-100 \%$ of individuals who do not apply for benefits. However, on this outcome, the sensitivity of the model is relatively low; predicting approximately 5-15\% of those who actually apply for benefits in wave 6. On employment status measures (any employment, full time employment and part time employment) the model is highly sensitive (about 95-100\%) and relatively specific (8598\%). Interestingly, the model is specific (approximately 95-100\%) in predicting who does not retire, but not very sensitive (4 to $10 \%$ ) in predicting who retires in 2002 . These patterns are similar for men and women.

For interpretation we compare these results to the predictive power of in-sample predictions. On employment status measures (any employment, full time employment and part time employment) and retirement, the predictive power of the model in the sample cohort is highly sensitive (98-100\%) and highly specific (98-100\%). Compared with the 2002 sample, the model does a better job predicting who will and will not work and who will and will not retire in the sample. For DI/SSI applications, our in sample model predictions are highly specific, predicting accurately $100 \%$ of men and women who do not apply for benefits. The sensitivity of our model's predictive power in the sample remains relatively low; predicting approximately 15$18 \%$ of men and women apply for benefits.

individuals who are predicted to have a negative outcome (i.e. do not apply for DI/SSI benefits, continue to work, do not retire) who actually do in 2002. 
Differences in the predictive capabilities of the model regarding employment and retirement behavior may be accounted for by several factors. First, macroeconomic conditions in 2000-2002, the time period captured in wave 6, were very different from conditions in 19942000, the period surveyed in waves 2 through 5. In particular, stock market valuations fell substantially in 2000-2002, reducing the value of accrued assets including retirement portfolios. In addition, employment overall fell during this period. Finally, data for wave 6 was released by the University of Michigan in the past several months. It has not been subjected to the same extensive cleaning of the previously released data. Therefore, some differences observed in comparing the in and out of sample predictive power of the models may be due to the preliminary nature of the data from 2002.

\section{Interpretation of Findings and Implications}

Results of both estimation strategies indicate that symptoms of depression directly increases DI/SSI application and early retirement and decreases work for men and women. This is consistent with the previous economic literature that permitted for distinctions between physical and mental illnesses. This finding is also consistent with recent cost of illness estimates suggesting that the costs of depression associated with workplace outcomes are significant. ${ }^{84}$ The magnitude of this effect appears to be of the same order of magnitude to that of physical illness both for men and for women and greater than that of widowhood alone.

Depression interacts significantly with physical illness in men and women to increase DI/SSI applications and early retirement and decrease full time labor force participation. Depression's indirect negative effect on work outcomes through its interaction with widowhood

84 Wang P, Simon SE, Kessler RC, 2003. The economic burden of depression and the cost-effectiveness of treatment. Int J Methods Psychiatr Res 12(1):22-33. 
is significant for men and women. Interestingly, this indirect effect appears to be differentially detrimental to men. This finding is consistent with the widower effect documented in the recent sociological literature. ${ }^{85,86}$

These findings have important implications for interpreting disability levels and trends. First, several recent economic papers have accounted for the role of health in determining DI/SSI applications and other labor force outcomes, but have measured health using changes in aggregate mortality. Aggregate mortality statistics are likely correlated with the morbidity associated with acute and some chronic diseases but represent a rather imprecise measure of the health of the population. In particular, chronic illnesses appear to play an increasingly central role in determining the health of the population. Our results suggest that mental illness alone and in combination with physical illness exert important influences on retirement behavior and DI/SSI applications consistent with recent disability application and recipiency trends. As such, they provide a more complete picture of how chronic disease and in particular mental illness impacts employment decisions, retirement and disability applications.

Second, our results have important implications for interpreting trends in disability overall. The results of the analyses suggest that the interaction between depression and physical illness is substantial and significantly impacts DI/SSI applications. Therefore, holding depression's indirect effect on disability constant, physical illness's role in disability may be decreasing faster than previous research suggests.

85 Iwashyna TJ, Christakis NA, 2003. Marriage, widowhood, and health-care use. Soc Sci Med 57(11):2137-47.

86 Christakis NA and Iwashyna TJ. The health impact of health care on families: a matched cohort study of hospice use by decedents and mortality outcomes in surviving, widowed spouses. Soc Sci Med. 2003 Aug;57(3):465-75. 
There have been significant advances in the treatment of major depression over the past two decades. One major limitation of our dataset is its lack of detailed information on treatment. It is important to understand the potential effect of receiving appropriate treatment has on employment outcomes. A recent meta-analysis identified eight papers directly addressing this question. 87 The authors conclude that interventions to enhance depression treatment can yield productivity gains, which appear to be small relative to the improvements in clinical outcomes. To put our results in this context, we gathered the following statistics: currently available data on the percentage of the general population who receives any depression treatment; ${ }^{11}$ among them, the percentage of individuals who receive treatment consistent with clinical guidelines; 88 and the response rate to treatment consistent with those guidelines. ${ }^{9}$ We then calculated the returns to guideline treatment in our study population, assuming treatment returns an individual to the likelihood of employment status enjoyed by non-depressed individual. The receipt of guideline treatment for depression in our study population would result in a 3-15\% percentage point reduction in adverse employment outcomes. The impact of treatment receipt on individual's lives may thus be substantial. Research quantifying the impact of treatment on labor market outcomes is an important area for future study.

87 Timbie JW, Frank, RG, Horvitz-Lennon M, Normand SL, 2005. A Meta-Analysis of the Effect of Enhanced Care for Depression on Work-Related Productivity. Unpublished manuscript, Harvard University.

88 Wells KB, Katon W, Rogers B, Camp P, 1994. Use of minor tranquilizers and antidepressant medications by depressed outpatients: results from the medical outcomes study. Am J Psychiatry 151(5): 694-7000. 


\begin{tabular}{|c|c|c|}
\hline \multicolumn{3}{|c|}{ Table 1: Description of Study Population } \\
\hline \multicolumn{3}{|l|}{ 1a. Strategy \#1 } \\
\hline & Men & Women \\
\hline Total $\mathrm{N}$ & 2,457 & 2,986 \\
\hline Average age at baseline & 54.6 & 52.3 \\
\hline$\%$ depressed at baseline & $6 \%$ & $12 \%$ \\
\hline $\begin{array}{l}\text { \% depressed at baseline and develop physical } \\
\text { illness }\end{array}$ & $30.30 \%$ & $18 \%$ \\
\hline$\%$ depressed at baseline and become widowed & $2.30 \%$ & $7.10 \%$ \\
\hline$\%$ develop physical illness, no depression & $20.30 \%$ & $13.50 \%$ \\
\hline$\%$ become widowed, no depression & $2.30 \%$ & $7.10 \%$ \\
\hline \multicolumn{3}{|l|}{ 1b. Strategy \#2 } \\
\hline & Men & Women \\
\hline Total N & 1,345 & 1,821 \\
\hline Average age at baseline & 54.6 & 52.5 \\
\hline$\%$ develop depression & $10 \%$ & $15 \%$ \\
\hline$\%$ develop physical illness & $18.30 \%$ & $13 \%$ \\
\hline$\%$ become widowed & $2.40 \%$ & $6.60 \%$ \\
\hline$\%$ develop depression and physical illness & $26.10 \%$ & $18.70 \%$ \\
\hline$\%$ develop depression and become widowed & $1.30 \%$ & 9 \\
\hline
\end{tabular}

\begin{tabular}{|c|c|c|c|c|c|c|c|c|}
\hline \multicolumn{9}{|c|}{ Table 2: Comparison of Baseline Characteristics Strategy \# 1} \\
\hline & \multicolumn{4}{|c|}{ Men } & \multicolumn{4}{|c|}{ Women } \\
\hline & \multicolumn{2}{|c|}{ not depressed } & \multicolumn{2}{|c|}{ depressed } & \multicolumn{2}{|c|}{ not depressed } & \multicolumn{2}{|c|}{ depressed } \\
\hline & mean & se & mean & se & mean & se & mean & se \\
\hline married & 0.88 & 0.007 & 0.7 & 0.04 & 0.74 & 0.009 & 0.67 & 0.02 \\
\hline $\begin{array}{l}\text { separated } \\
\text { or divorced }\end{array}$ & 0.08 & 0.008 & 0.104 & 0.02 & 0.11 & 0.007 & 0.13 & 0.02 \\
\hline $\begin{array}{l}\text { less than a } \\
\text { high school } \\
\text { education }\end{array}$ & 0.19 & 0.008 & 0.42 & 0.04 & 0.16 & 0.007 & 0.36 & 0.03 \\
\hline black & 0.12 & 0.007 & 0.12 & 0.03 & 0.17 & 0.007 & 0.22 & 0.02 \\
\hline hispanic & 0.07 & 0.007 & 0.18 & 0.02 & 0.07 & 0.005 & 0.21 & 0.02 \\
\hline $\begin{array}{l}\text { has private } \\
\text { health } \\
\text { insurance }\end{array}$ & 0.08 & 0.008 & 0.57 & 0.04 & 0.8 & 0.008 & 0.65 & 0.03 \\
\hline $\begin{array}{l}\text { nonhousing } \\
\text { assets }\end{array}$ & 72147.9 & 3352.9 & 64067 & 6103 & 61762.31 & 1639.2 & 40717 & 2808.3 \\
\hline
\end{tabular}




\begin{tabular}{|c|c|c|c|c|c|c|c|c|c|c|}
\hline \multirow[t]{2}{*}{ Outcome } & \multicolumn{2}{|c|}{$\begin{array}{c}\text { baseline } \\
\text { depression }\end{array}$} & \multicolumn{2}{|c|}{$\begin{array}{c}\text { subsequent } \\
\text { physical } \\
\text { condition }\end{array}$} & \multicolumn{2}{|c|}{$\begin{array}{c}\text { interaction } \\
\text { baseline } \\
\text { depression and } \\
\text { physical } \\
\text { condition } \\
\end{array}$} & \multicolumn{2}{|c|}{$\begin{array}{l}\text { subsequent } \\
\text { widowhood }\end{array}$} & \multicolumn{2}{|c|}{$\begin{array}{c}\text { interaction } \\
\text { baseline } \\
\text { depression anc } \\
\text { widowhood }\end{array}$} \\
\hline & $\beta$ & se & $\beta$ & se & $\beta$ & se & $\beta$ & se & $\beta$ & se \\
\hline \multicolumn{11}{|c|}{ Men } \\
\hline \multicolumn{11}{|l|}{ DI/SSI Application } \\
\hline $\begin{array}{r}\text { applies or re- } \\
\text { applies for } \\
\text { disability } \\
\text { insurance }\end{array}$ & 0.45 & 0.16 & 0.46 & 0.13 & 0.32 & 0.17 & 0.09 & 0.29 & 0.57 & 0.5 \\
\hline \multicolumn{11}{|c|}{ Employment Status } \\
\hline works & -0.92 & 0.88 & -0.4 & 0.07 & -0.16 & 0.17 & -0.007 & 0.2 & -0.77 & 0.34 \\
\hline $\begin{array}{r}\text { works at a full } \\
\text { time job }\end{array}$ & 0.06 & 0.1 & -0.3 & 0.06 & -0.35 & 0.15 & -0.12 & 0.19 & -0.38 & 0.26 \\
\hline $\begin{array}{r}\text { works at a part } \\
\text { time job }\end{array}$ & -0.11 & 0.16 & -0.04 & 0.1 & 0.12 & 0.17 & 0.002 & 0.29 & 0.66 & 0.47 \\
\hline \multicolumn{11}{|l|}{ Retirement } \\
\hline $\begin{array}{r}\begin{array}{r}\text { leaves labor } \\
\text { force }\end{array} \\
\end{array}$ & 0.25 & 0.14 & 0.14 & 0.07 & 0.29 & 0.15 & 0.08 & 0.2 & 0.24 & 0.43 \\
\hline \multicolumn{11}{|c|}{ Women } \\
\hline \multicolumn{11}{|l|}{ DI/SSI Application } \\
\hline $\begin{array}{r}\text { applies or re- } \\
\text { applies for } \\
\text { disability } \\
\text { insurance }\end{array}$ & 0.63 & 0.14 & 0.42 & 0.11 & 0.24 & 0.16 & 0.002 & 0.15 & 0.55 & 0.2 \\
\hline \multicolumn{11}{|c|}{ Employment Status } \\
\hline works & -0.74 & 0.75 & -0.25 & 0.08 & -0.21 & 0.2 & -0.11 & 0.12 & 0.03 & 0.24 \\
\hline $\begin{array}{r}\text { works at a full } \\
\text { time job }\end{array}$ & -0.08 & 0.08 & -0.09 & 0.06 & -0.21 & 0.24 & -0.21 & 0.11 & -0.08 & 0.11 \\
\hline $\begin{array}{r}\text { works at a part } \\
\text { time job }\end{array}$ & -0.16 & 0.12 & -0.07 & 0.07 & 0.14 & 0.17 & 0.1 & 0.12 & -0.42 & 0.22 \\
\hline \multicolumn{11}{|l|}{ Retirement } \\
\hline $\begin{array}{r}\text { leaves labor } \\
\text { force }\end{array}$ & 0.47 & 0.15 & 0.11 & 0.08 & 0.1 & 0.2 & 0.14 & 0.12 & 0.13 & 0.24 \\
\hline
\end{tabular}

significant at the $p=0.05$ level 
Graph 1a. Strategy \#1, DI/SSI Application, Men

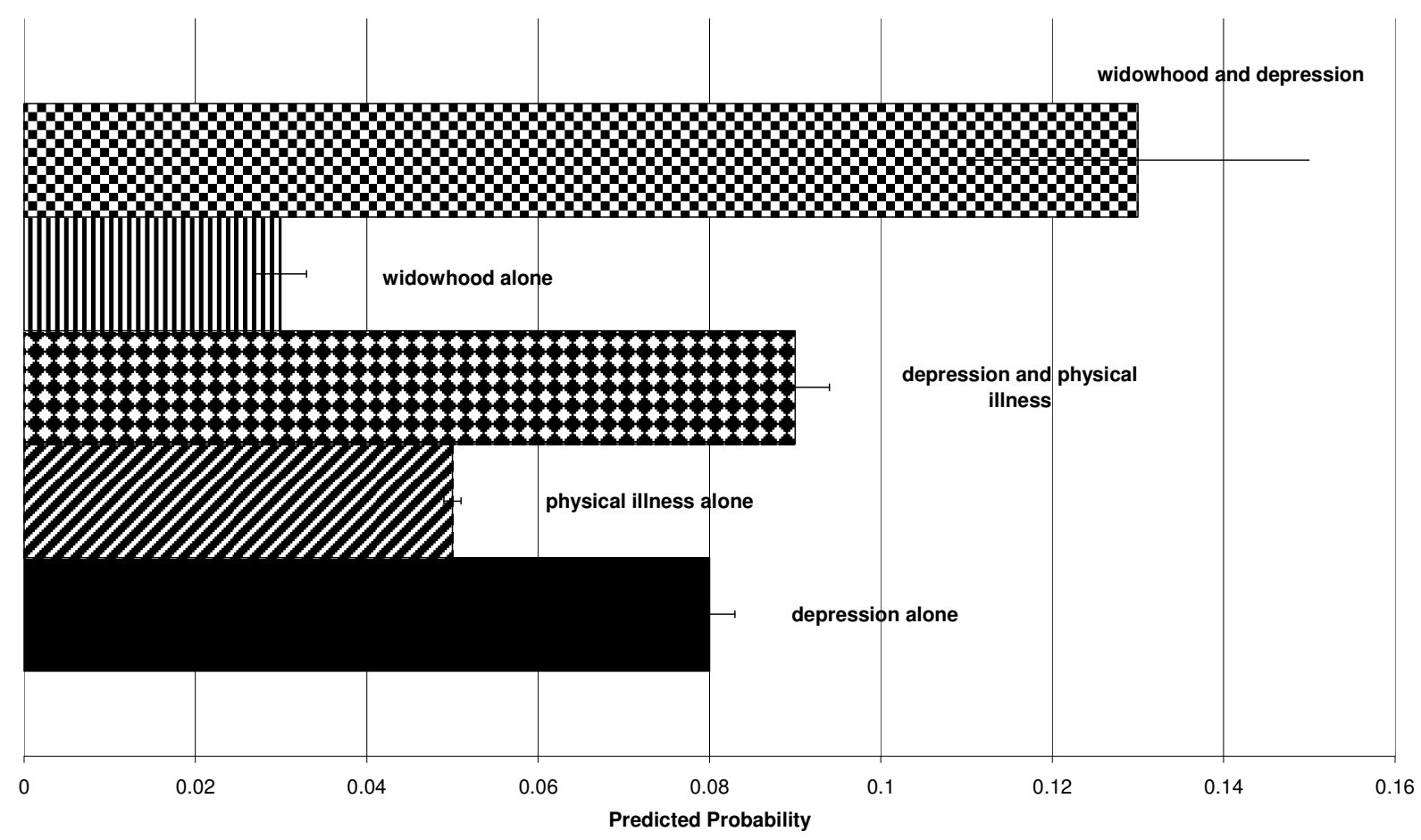

Chart 1b. Strategy \#1, DI/SSI Applications, Women

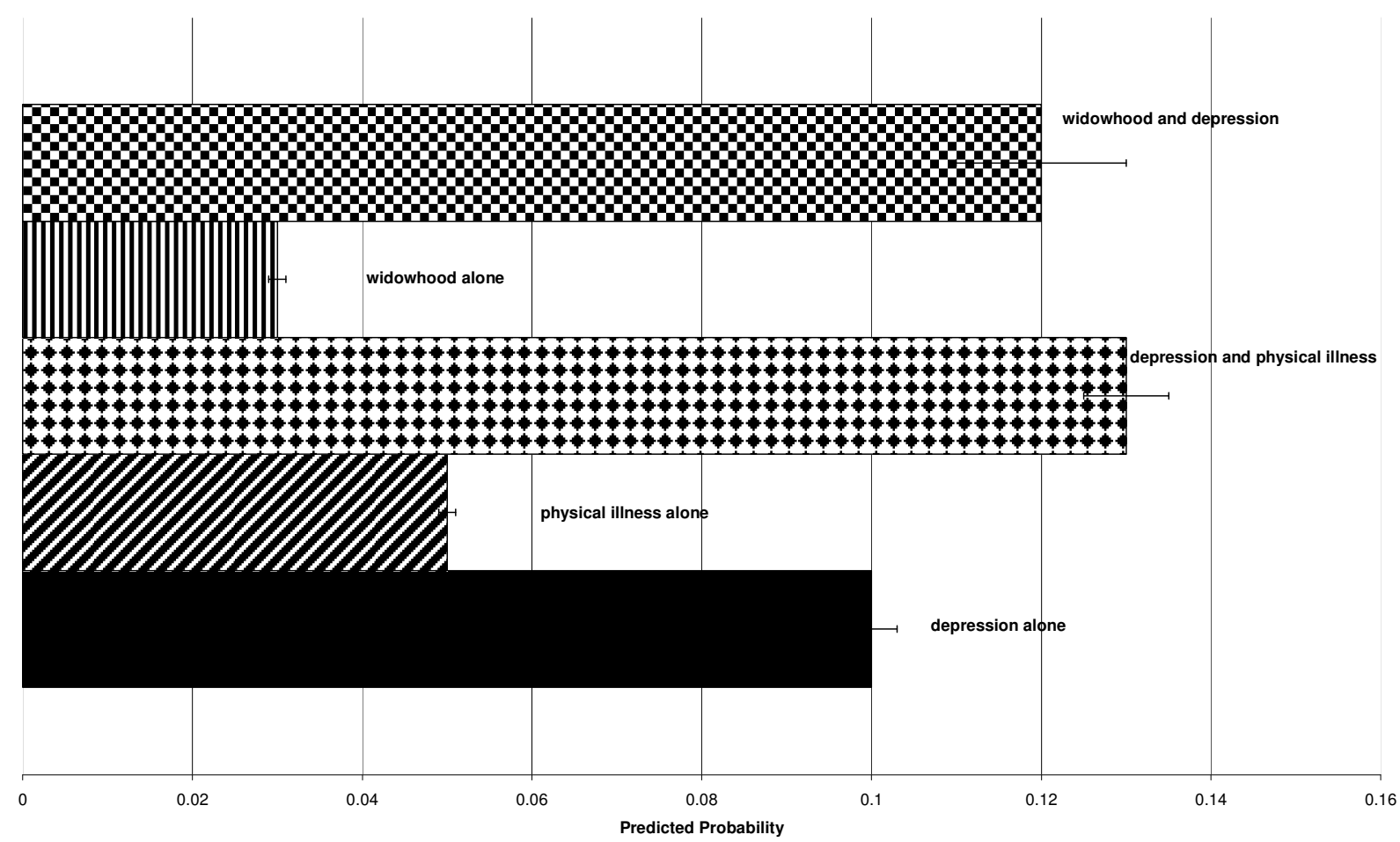


Chart 2a. Strategy \#1, Early Retirement, Men

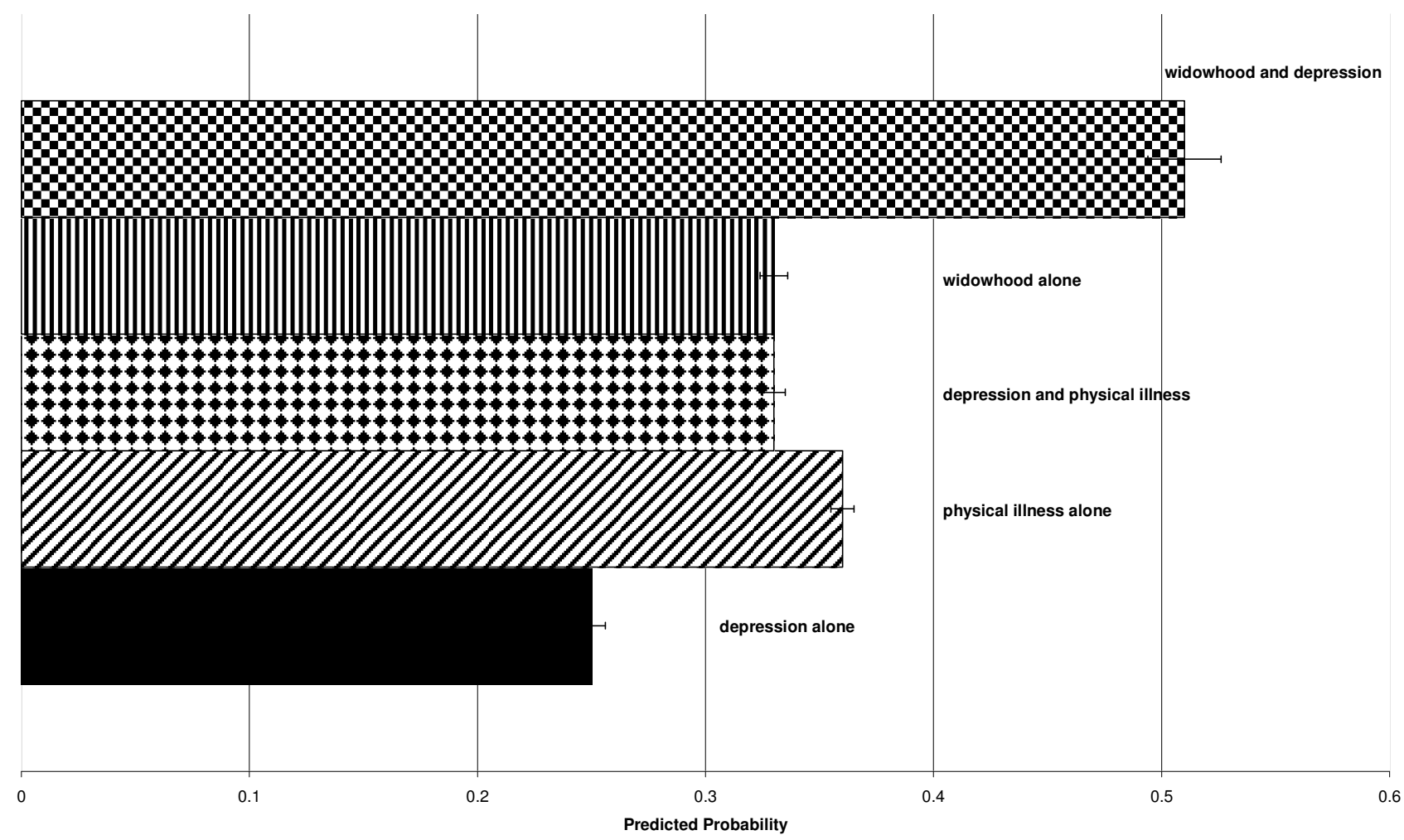

Chart 2b. Strategy \#1, Early Retirement, Women

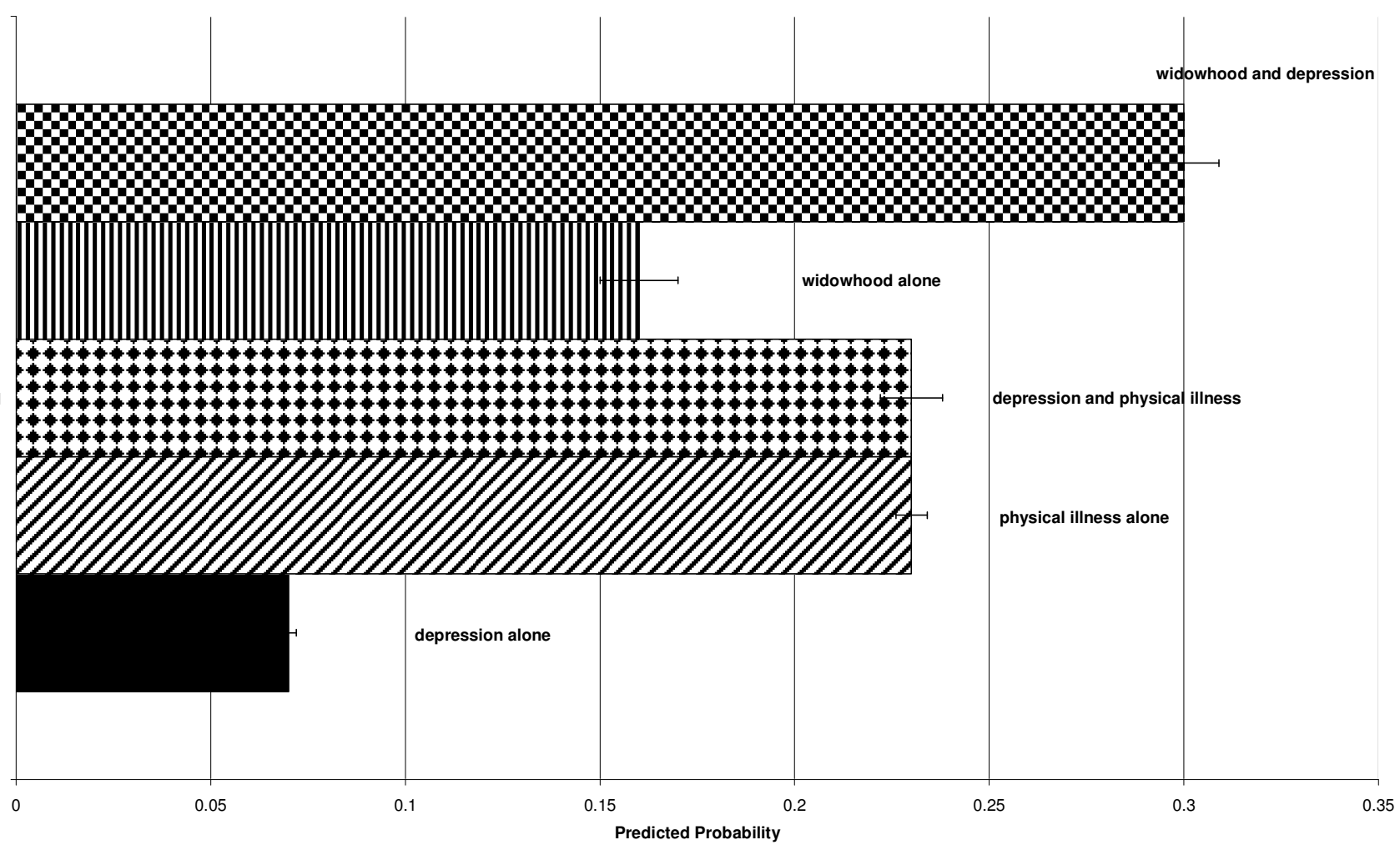




\begin{tabular}{|c|c|c|c|c|c|c|c|c|c|c|}
\hline \multicolumn{11}{|c|}{ Table 4: Strategy \#2 GEE Results by Gender } \\
\hline \multirow[t]{2}{*}{ outcome } & \multicolumn{2}{|c|}{$\begin{array}{l}\text { subsequent } \\
\text { depression }\end{array}$} & \multicolumn{2}{|c|}{$\begin{array}{c}\text { subsequent } \\
\text { physical } \\
\text { illness }\end{array}$} & \multicolumn{2}{|c|}{$\begin{array}{c}\text { interaction } \\
\text { depression } \\
\text { and physical } \\
\text { illness }\end{array}$} & \multicolumn{2}{|c|}{$\begin{array}{l}\text { subsequent } \\
\text { widowhood }\end{array}$} & \multicolumn{2}{|c|}{$\begin{array}{c}\text { interaction } \\
\text { depression } \\
\text { and } \\
\text { widowhood }\end{array}$} \\
\hline & $\beta$ & se & $\bar{\beta}$ & se & $\beta$ & se & $\beta$ & se & $\beta$ & se \\
\hline \multicolumn{11}{|c|}{ Men } \\
\hline \multicolumn{11}{|c|}{ DI/SSI Application } \\
\hline $\begin{array}{r}\text { applies or re- } \\
\text { applies for } \\
\text { disability } \\
\text { insurance }\end{array}$ & 0.26 & 0.12 & 0.22 & 0.11 & 0.49 & 0.19 & 0.06 & 0.23 & 0.67 & 0.4 \\
\hline \multicolumn{11}{|c|}{ Employment Status } \\
\hline works & -0.26 & 0.09 & -0.29 & 0.1 & -0.13 & 0.18 & -0.09 & 0.23 & -0.6 & 0.32 \\
\hline $\begin{array}{r}\text { works at a full } \\
\text { time job }\end{array}$ & -0.08 & 0.07 & -0.2 & 0.07 & -0.32 & 0.19 & -0.15 & 0.16 & -0.5 & 0.26 \\
\hline $\begin{array}{r}\text { works at a } \\
\text { part time job }\end{array}$ & -0.03 & 0.11 & -0.12 & 0.11 & 0.33 & 0.2 & -0.06 & 0.25 & 0.73 & 0.46 \\
\hline \multicolumn{11}{|l|}{ Retirement } \\
\hline $\begin{array}{r}\text { leaves labor } \\
\text { force }\end{array}$ & 0.12 & 0.09 & 0.35 & 0.09 & 0.05 & 0.17 & 0.11 & 0.23 & 0.62 & 0.32 \\
\hline \multicolumn{11}{|c|}{ Women } \\
\hline \multicolumn{11}{|c|}{ DI/SSI Application } \\
\hline $\begin{array}{r}\text { applies or re- } \\
\text { applies for } \\
\text { disability } \\
\text { insurance }\end{array}$ & 0.16 & 0.1 & 0.34 & 0.1 & 0.43 & 0.17 & -0.05 & 0.12 & 0.61 & 0.17 \\
\hline \multicolumn{11}{|c|}{ Employment Status } \\
\hline works & -0.24 & 0.08 & -0.22 & 0.09 & -0.27 & 0.18 & 0.04 & 0.09 & -0.2 & 0.17 \\
\hline $\begin{array}{r}\text { works at a full } \\
\text { time job }\end{array}$ & -0.02 & 0.06 & -0.01 & 0.09 & -0.37 & 0.24 & 0.04 & 0.08 & -0.08 & 0.09 \\
\hline $\begin{array}{r}\text { works at a } \\
\text { part time job }\end{array}$ & -0.22 & 0.08 & -0.13 & 0.1 & -0.05 & 0.17 & 0.03 & 0.1 & -0.14 & 0.16 \\
\hline \multicolumn{11}{|l|}{ Retirement } \\
\hline $\begin{array}{r}\text { leaves labor } \\
\text { force }\end{array}$ & 0.18 & 0.08 & 0.22 & 0.09 & 0.26 & 0.18 & -0.06 & 0.09 & 0.23 & 0.17 \\
\hline
\end{tabular}


Chart 3a. Strategy \#2, DI/SSI Applications, Men

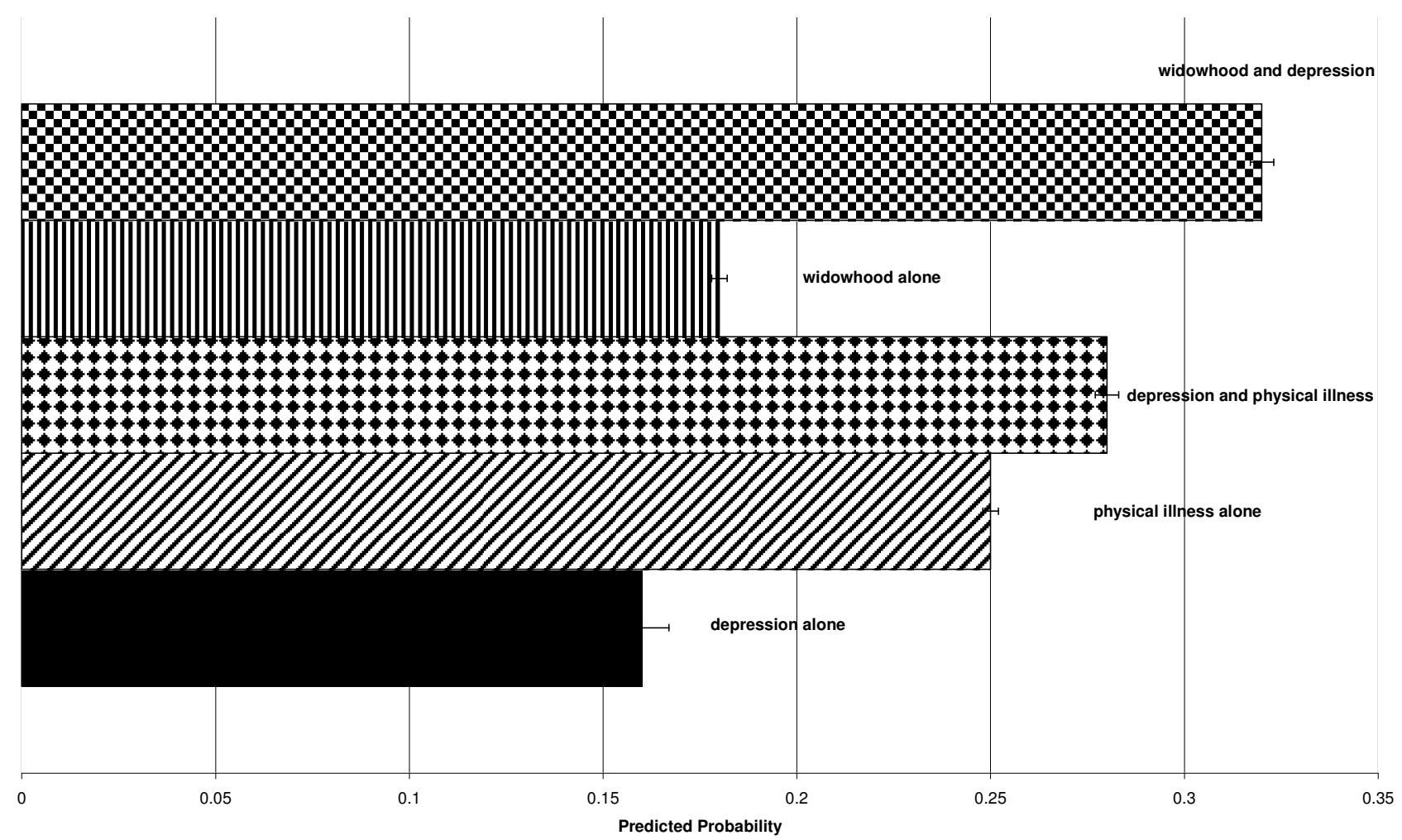

Chart 3b. Strategy \#2, DI/SSI Applications, Women

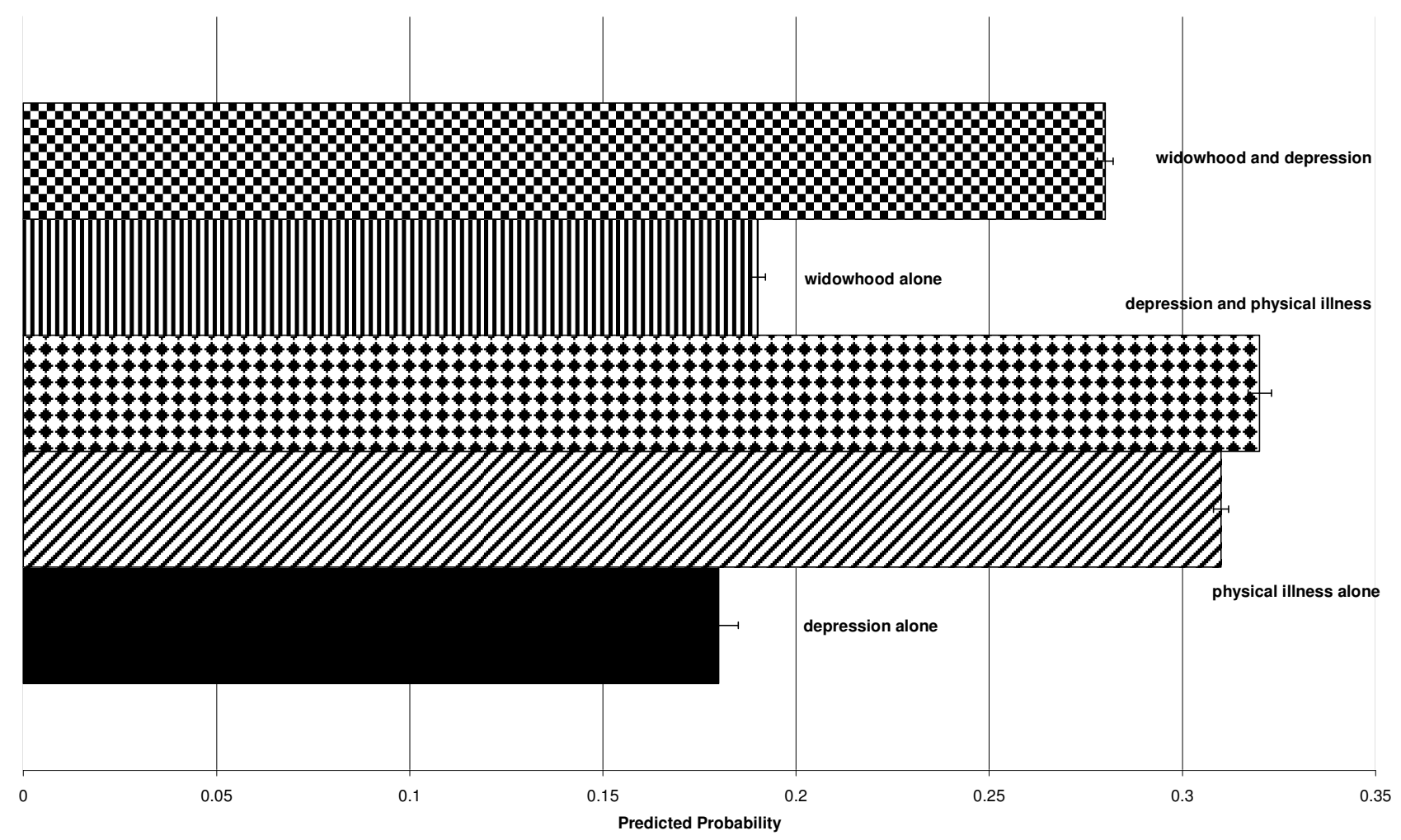




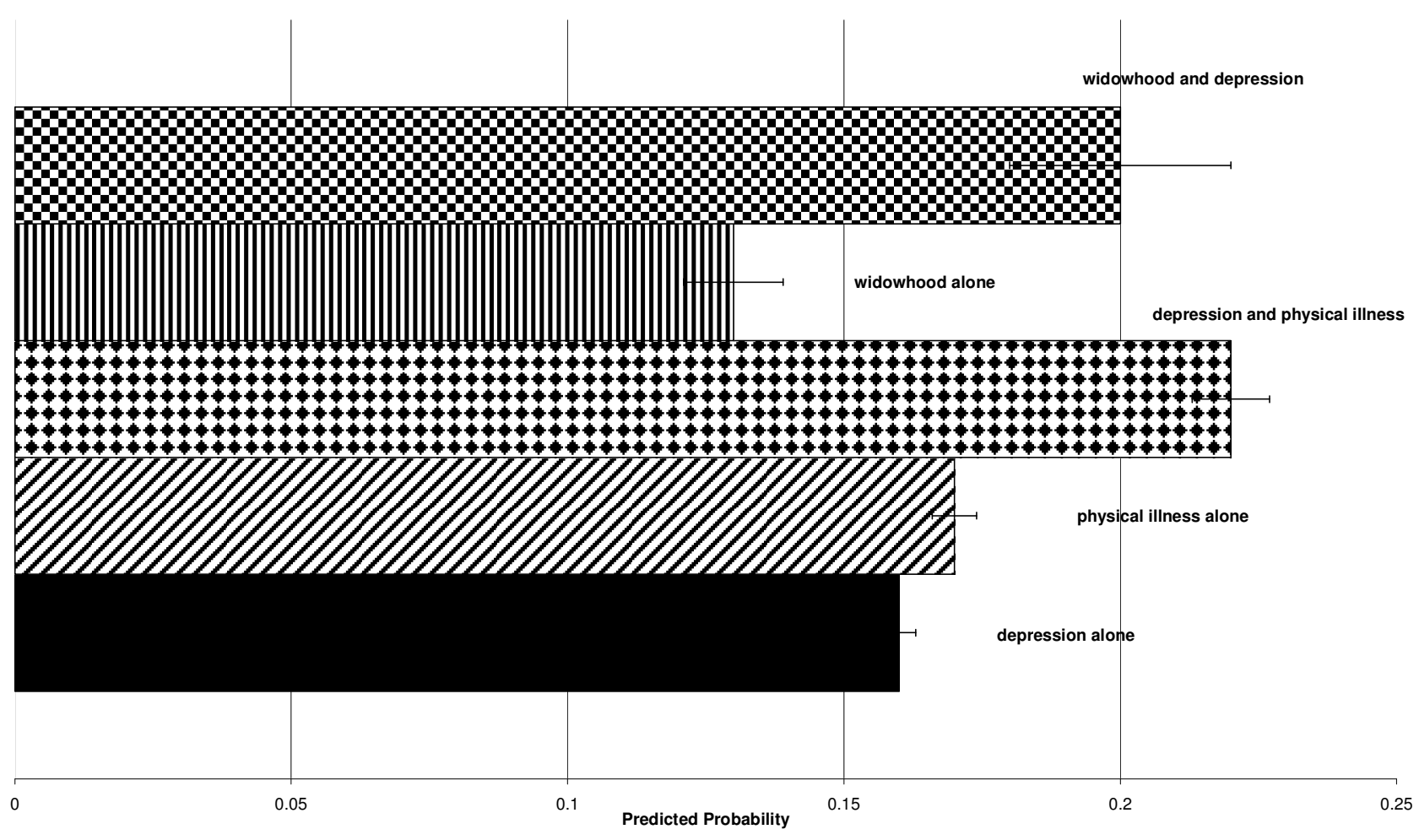

Chart 4b. Strategy \#2, Early Retirement, Women

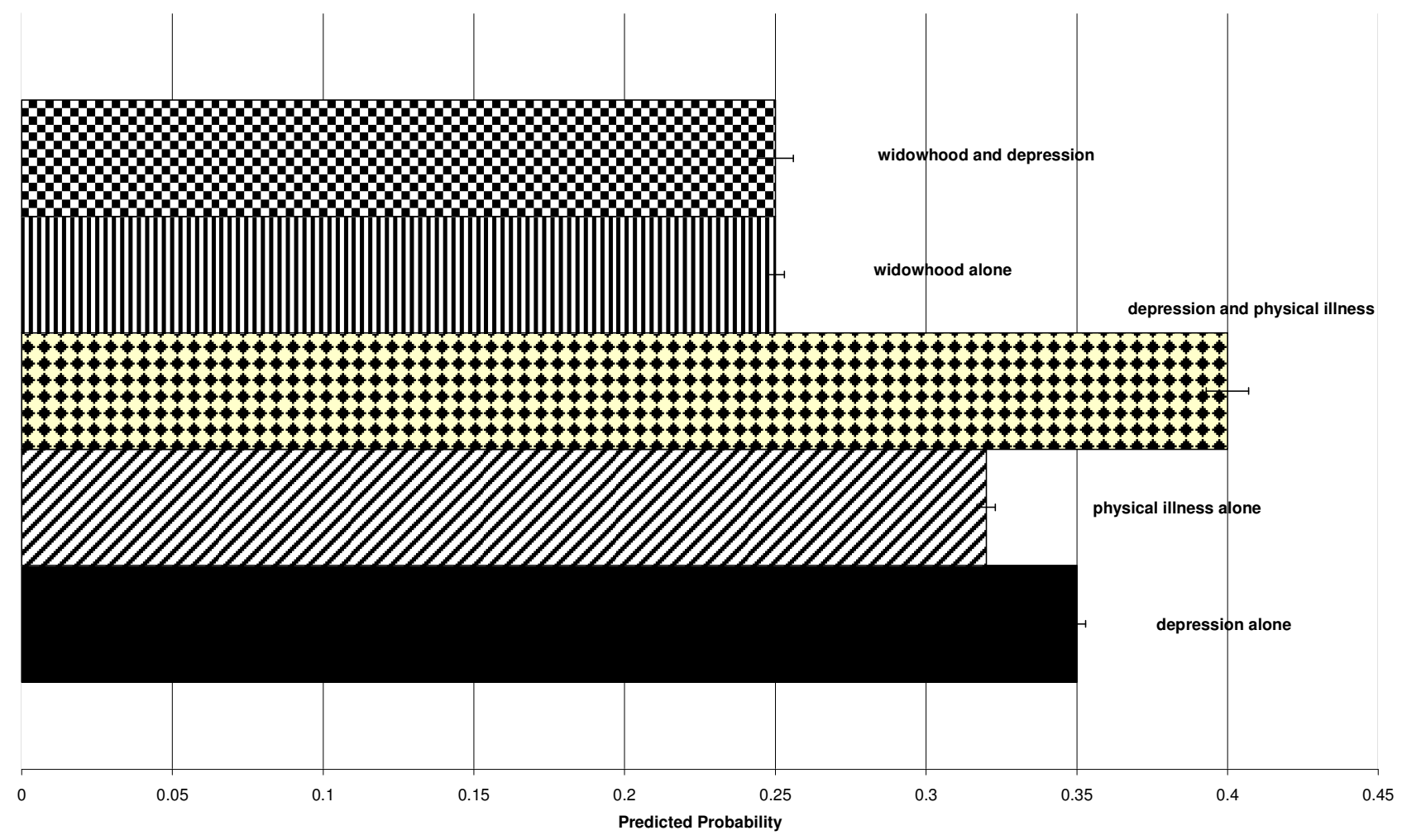

